Acta Crystallographica Section A

Foundations of

Crystallography

ISSN 0108-7673

\section{John M. Cowley FAA FRS (1923-2004)}

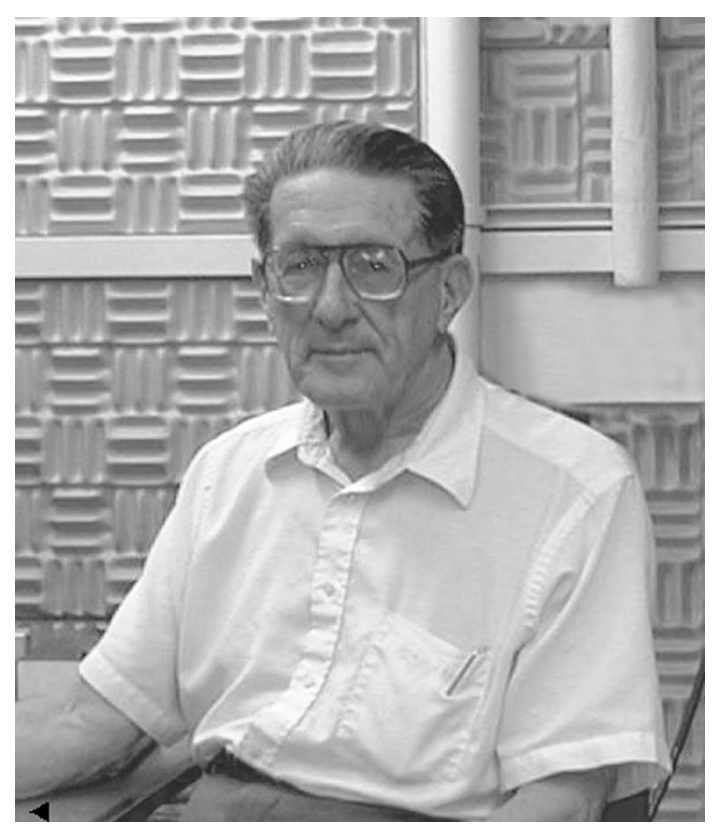

With the death of John Cowley, the worlds of crystallography, microscopy and materials have lost a great scientist. Those who knew him personally have lost a friend, and those of us who had the privilege of working with him have lost, in addition, a mentor. For working with John was a remarkable experience. His insight into the fundamental physics underlying some, frequently complex, phenomenon was profound and allowed him to describe, and then analyse, the situation in often deceptively simple, but in fact decisive, mathematical language.

John's abilities were appreciated early in his life, both by his family and by his school. Entering the University of Adelaide in 1940, he obtained a first class honours in physics in 1943 and an MSc in 1945, and it was in those latter years that he first encountered electron diffraction.

His work in Adelaide brought him to the attention of Dr Lloyd Rees, who encouraged him to join the Chemical Physics Section in CSIRO, the government research organization of Australia. Within the next three years, he had brought into operation an X-ray diffractometer, collaborated in the design and operation of a high-resolution electron diffraction camera and, with a number of colleagues, published papers in subjects ranging from the structure of minerals and yielding in steel, to lubrication, and the refraction of electrons in polyhedral crystals.

To undertake the design of a high-resolution electron diffraction camera typifies John's outlook. It was conventional wisdom that nothing significant remained to be resolved, but John never allowed himself to be over-influenced by authority. In this he was in entire agreement with his section leader and, as it emerged, with the young theorist, Norio Kato.

At this juncture, John was granted leave of absence to study under the direction of Professor R. Warren, in MIT. It was here that, arguably, he first 
attracted wide international attention, with his work, experimental and theoretical, on ordering in alloys. Starting from Bragg-Williams' foundations, this development has proved to be seminal, and few metallurgists would fail to recognize the patterns deriving from the memorable analysis of $\mathrm{Cu}_{3} \mathrm{Au}$.

On his return to Melbourne, two main themes emerged in his work, the extraction of structural information from single-crystal electron diffraction patterns, and the quantitative analysis of dynamical fine structure, the latter investigations carried out in collaboration with Goodman and Rees. It was here that contact was made with the work of Norio Kato, who always regarded the references to and the utilization of his theoretical predictions in the subsequent publication in Acta Crystallographica as a turning point in his career.

Shortly afterwards, another theme came to occupy John, namely $n$-beam scattering. Technically, the theory derives from a combination of the analysis of the self-imaging of periodic objects, Fourier imaging and a formulation of the optics of multi-component systems which developed from it. This formulation suggested the possibility of describing a crystal as a multislice system, and then establishing continuity by taking an impulse limit. The solution that emerged has found extensive application in both diffraction and microscopy.

With collaborators in increasing numbers and from all quarters of the world gathering round him, John's high abilities as a teacher became more and more apparent and led, most appropriately, to his accession to the Chamber of Manufacturers Chair of Physics in the University of Melbourne in 1962. Here he set up a school of extraordinary productivity, numbering amongst its graduates some of the most distinguished current workers in the field. He extended his investigations into many-beam scattering, and devoted attention to inelastic interactions and their influence on both diffraction patterns and images. At the same time, he revisited his work on short-range order and, along with his collaborators, extended and refined his already powerful formulation.

From the time of von Laue, the symmetry of reciprocity has occupied the attention of a great variety of crystallographers, and John was adept in exploiting it. A notable example is afforded by an important and apparently simple paper which he published in 1969, and which, at a stroke, established, under conditions of $n$-beam interaction, the relationship between images generated by transmission electron microscopy and those generated by scanning transmission microscopy. The paper, however, is also significant in revealing the direction in which John's approach to research was turning, namely towards the development of a highly individual scanning instrument.

In 1970, John accepted an appointment to the Galvin Professorship of Physics at Arizona State University. Here he again attracted a most distinguished research group, including a number of his colleagues from Melbourne University, notably John Spence and David Smith, and it was here that he wrote Diffraction Physics, the book that a whole generation of workers have found central to their subject. Here also his outstanding qualities as an administrator and leader were greatly in evidence, for instance in his founding and direction of the NSF national centre for high-resolution microscopy.

Although much occupied with the design of his scanning instrument, John maintained his interest in transmission electron microscopy and launched into a fruitful collaboration with both Sumio Iijima, a post-doctoral fellow, and with the groups in CSIRO engaged in the study of the structure of block oxides, a subject deriving from Wadsley's X-ray investigations. The two-dimensional lattice images generated in the course of this work constituted dramatic evidence of the emergence of a new and powerful phase in electron microscopy. 
With the installation of the VG HB-5, a scanning transmission instrument fitted with a cold emitter, John embarked on a programme that was to occupy him for much of the rest of his life and that opened up a new field, one incorporating aspects of diffraction, microscopy, holography and spectroscopy. The amalgamations involved radically new designs and theory, completely characteristic of Cowley, and produced results qualitatively different from those deriving from successive measurements. For instance, Goodman and Dowell had demonstrated that, with a sufficiently small source, overlapping discs in electron diffraction convergent-beam patterns display interference, so that 'dynamical' phase can be measured directly. This effect is exploited in one configuration of the HB-5 in such a way that data are generated from which images can be calculated to an effective resolution of two Bohr radii, that is, four times smaller than the diameter of the probe, thereby accessing resolutions of a hitherto unattainable level. A description of some extensions and applications of this technique forms the subject of John's last published paper.

It is perhaps fitting that one of the last projects that John initiated, and in which he was involved at the time of his death, displays the depth and boldness that is to be found in the design and construction of the first simple microscope. In fact, he was engaged in the operation of what is presumably the ultimate Leeuwenhoek objective, an atom. Fortunately, he and a number of his colleagues have published the first results deriving from this enterprise so that at least some of his insights into the field that will be accessed by imaging at a new order are available to all of us.

Enduring personal memories are of John's calm, of his readiness to share his profound insights, and of his patience with those of us less able than himself.

Among his many honours and awards, those most directly concerned with crystallography are his membership of the Commission on Electron Diffraction at various periods between 1957 and 1993, his membership of the Executive Committee of the IUCr from 1963 to 1969, his representation of the IUCr on the Commission for Solid State Physics of IUPAP from 1969 to 1978, his Coeditorship of Acta Crystallographica from 1971 to 1980, his sharing of the Bertram Eugene Warren Award of the American Crystallographic Association in 1976 and his sharing of the Ewald Prize of the IUCr in 1987.

\author{
Alex Moodie \\ Royal Melbourne Institute of Technology \\ 124 Latrobe Street \\ Melbourne \\ Victoria 3000 \\ Australia \\ E-mail: alex.moodie@rmit.edu.au
}

